\title{
Research on the Construction of Agricultural Product Quality Supervision System based on E-commerce
}

\author{
Yu'e Yang \\ Xi’an International University, Xi'an, Shaanxi, 710077
}

Keywords: Agricultural Product, Quality Supervision, E-commerce.

\begin{abstract}
E-commerce of agricultural products refers to the modern information technology and business means into the production and distribution of agricultural products in the sales process, through the information network technology for agricultural information dissemination and collection, and in the network to achieve product trading means. The e-commerce of agricultural products has realized the effective link between the supply side of the agricultural products and the demand side, not only solved the problem of selling agricultural products, but also realized the interests of the farmers to maximize. With the popularity of rural e-commerce, including fresh products, including agricultural products, e-commerce has been rapid development of agricultural products has become a new type of circulation into another major commodity system. Quality and safety standards are an important guarantee for ensuring the safe consumption of agricultural products sold in the network. However, due to the lag of standard construction, the existing standards are difficult to meet the new sales model of e-commerce. Agricultural product quality and safety standards should be adapted to the needs of e-commerce, develop and improve the supporting standards for the development of agricultural e-commerce and security supervision to provide protection.
\end{abstract}

\section{Introduction}

The main factors influencing the e-commerce of agricultural products are the added value and the transaction cost of the product, and the standardization degree of the product is the key point that affects these two factors. Certified agricultural products have a high degree of standardization, product characteristics easy to describe, consumers of these products, a high degree of recognition in the e-commerce model is easy to succeed. Fresh products, low value-added products, high transport costs, but also in the transport process easily perishable, affecting the quality and safety of products, is more difficult to achieve e-commerce agricultural products. But for the same type of agricultural products, the high degree of standardization in the e-commerce operations will increase the cost of relatively low. From the current agricultural e-commerce business model, fresh food is the focus of agricultural product quality and safety supervision and difficulties. Fruits and vegetables, meat, live animals, such as crabs and other agricultural products through the traditional sales channels to enter the market, the market side or the business sector to test, such as meat need to provide qualified quarantine certificate to market. The network sales of agricultural products, quarantine proved difficult to distinguish the authenticity. Food safety management departments through the sampling, supervision and inspection, etc. to ensure the quality and safety of traditional agricultural products, and e-commerce model of agricultural products from the production base directly to the hands of consumers, only the origin of regulation to ensure product safety. The distinction between e-commerce and traditional circulation of agricultural products In the e-commerce model, there is a need for matching standards to meet the needs of quality and safety management. Product standardization directly affects the correct transmission of agricultural products or not. Quality and safety standards mainly in government regulation, e-commerce model compared to the traditional sales model, can achieve less regulatory links. Due to the quality and safety standards of agricultural products, the indicators are complex, the detection cost is high, and the logistics links affect the quality and safety of agricultural products, uncontrollable factors are 
more. Therefore, in the e-commerce model, the need for agricultural product quality and safety standards to reflect the origin of the product safety, good quality, geographical characteristics, logistics and other characteristics.

\section{Quality and Safety Supervision of Agricultural Products in E-commerce Environment}

The main problems of quality and safety supervision of agricultural products in the environment of e-commerce are as follows. The quality and safety of agricultural production in the environment of e-commerce The abuse of chemical fertilizers, pesticides and hormones in the process of agricultural production directly leads to the quality and safety of agricultural products. In the e-commerce environment, the quality and safety of deep processing of agricultural products in the process of the lack of processing of agricultural products, the concept of processing technology and equipment at the same time, deep processing of agricultural products in the process of illegal use of additives, shoddy, short jin two, cut corners and poor production environment And other issues directly lead to the quality of agricultural products processing quality and safety issues. Under the electronic commerce environment, the quality and safety of agricultural products in the circulation of agricultural products in the circulation, not strict warehouse management, simple and inefficient logistics and transportation of agricultural products will have a serious impact on food safety.

Traditional agricultural product quality and safety standards and more to the end of the main control, to produce the product testing qualified for quality control objectives. In the e-commerce model, the focus of agricultural product quality and safety standards is different, to ensure that in accordance with the standard recognized as a qualified production base, in accordance with the standards of operating procedures to produce qualified agricultural products as the focus. As the source of agricultural sales of agricultural products has a great diversity, the actual situation of farmers operating different, in accordance with the traditional food regulatory system for all the certification, the lack of realistic feasibility.

\section{E-Commerce of Agricultural Product Quality and Safety Supervision System}

Demand for grade specification standards Successful agricultural products E-commerce requirements Online trade of agricultural products Quality grading Standardization \& packaging standardization and product coding, requires agricultural products have a certain brand. At present, some sites have made some attempts to standardize agricultural products, classified according to the classification of agricultural products, issued the corresponding standard description, and in accordance with the standard acquisition. But most of the agricultural production and management model is more extensive, mostly non-standardized empirical products, consumers must use after the object to make an objective evaluation of the goods, and a wide range of agricultural products, reflecting the product quality indicators are complex and diverse, to the agricultural standardization zone To great difficulty. China's agricultural products are rich in species, geographical differences, in recent years, agricultural industry standards and local standards to develop a large number of products and grade specifications. Agricultural grade standard is to guide agricultural production, regulate the market circulation of an important means to further promote the production and marketing convergence, play a leading role in the production of circulation. But in e-commerce, the existing level of standard specifications is difficult to describe the characteristics of agricultural products, many businesses are more inclined to directly use their own products to describe the characteristics of the product specifications. At the same time in the network of successful sales of agricultural products for local characteristics of products, due to good quality or its unique by consumers, the lack of related products and grades of agricultural industry standards or local standards. At present, the agricultural industry standard will also be the general product standards, grade specifications category included in the clean-up areas, the future will not be focused on the development. Enterprise standard is an important part of our standard system, for product quality and grade specifications are difficult to uniform case, the use of corporate standards to regulate more reasonable. In the e-commerce model, should give full play to enterprise standards for 
agricultural product quality and safety management of the normative role.

Demand for regional characteristics of product standards E-commerce model, the regional characteristics of products because of its unique quality and flavor, sales more successful. China's vast territory, the production of Hangzhou Longjing tea, Xinjiang Hami melon, Changshan Huyou, Ningxia wolfberry and other characteristics of agricultural products, China's current geographical indications products have 55. The promulgation and implementation of the standard of geographical indication products has promoted the brand building of agricultural products in China, and it is easy to obtain the trust and recognition of consumers in the network propaganda. Zhejiang Province for the production of agricultural products, climate resources, the implementation of the agricultural product climate certification, has been completed tea, Yangmei, grapes, citrus, pears, rice and other eight categories of 57 batches of agricultural products, climate certification, to improve the market competitiveness of agricultural products and Product added value has played a role in promoting h5i. Geographical indications products and climate quality certification are the promotion of agricultural products brand. Regional characteristics of agricultural products in the local government and the relevant management departments to promote publicity, to promote product sales, improve farmers' income has a good role in promoting. In the e-commerce model, the combination of such standards and certification will promote the improvement of agricultural product quality and safety.

Demand for the production of technical specifications of China's agricultural production before the majority of extensive management, the production process of the abuse of pesticides, fertilizers, irrational cultivation of agricultural products on the quality and safety poses a threat, but also damage to the ecological environment. Safe agricultural products from the good management of the production process, learn from the experience of developed countries, China through the implementation of agricultural standardization demonstration area construction, the implementation of the whole process of standardized production, speed up the transformation and upgrading of traditional agriculture and improve the quality and safety of agricultural products $h$ (i. Mode, the need for government regulation of quality and safety of agricultural products forward, the most critical is to ensure that the production base of product safety through pollution-free, green or organic certification of agricultural products, quality and safety is guaranteed, easier to get consumer trust.

Demand for agricultural logistics standards Logistics is an important part of e-commerce of agricultural products, and has important influence on the quality and safety of agricultural products, especially fresh products. E-commerce requires logistics fast, standard, or through the cold chain transport, to control a certain transport conditions to ensure that the product appearance, quality, microbial within the standard range. The products such as e-commerce products is on the logistics standards of the highest, Taobao, Jingdong, Suning, SF and other current efforts to develop fresh products e-commerce h4i. Logistics standards include the acquisition standards, storage standards, transport process control standards, distribution standards. Logistics is the convergence of e-commerce model of agricultural products suppliers and consumers of the intermediate links, logistics standardization is also dependent on the improvement of production standardization.

The demand for traceability of agricultural products The traceability of agricultural products is an effective tool to ensure quality and safety. E-commerce is a transaction between unfamiliar suppliers and consumers. It is also necessary to ensure quality and safety through traceability. Relative to the traditional agricultural products sales, e-commerce transactions less traceability technology should be relatively easy to achieve. At present, the relevant departments in the country, has been in the beef, vegetables, fruits, aquatic products and other aspects of the implementation of traceability system, through bar code, radio frequency technology applications, the establishment of traceable system production base. The realization of the source system is based on information technology, e-commerce itself is based on the development of information technology, so there is the basis for the implementation of traceability.

\section{Conclusion}

The countermeasures of optimizing the quality and safety of agricultural products under the 
environment of e-commerce can be started from the aspects of building large-scale agricultural products e-commerce platform, promoting the rationalization and transfer of the main body of food safety supervision, strengthening the brand marketing of agricultural products and cultivating food safety awareness. For example, the concept of agricultural product logistics BGA business model is based on the idea of Internet business model. As shown in Figure 2, the BGA business model is a systematic business model for the integration of agricultural resources through the establishment of a large-scale e-commerce platform, the implementation of the whole process of food safety and efficient circulation of standardized government regulation to activate the local rural collective economy based on the integration of agricultural business model, , So that food safety supervision to be effective.

\section{Acknowledgements}

2017 Xi'an social science planning fund project: Study on the supervision system of agricultural products quality safety based on e-commerce in Xi'an (17IN10)

\section{References}

[1] Luo Yi. Some Thoughts on the Development of E-commerce in Agricultural Products in China Based on a Study of Multiple Cases [J]. China Circulation Economics, 2012 (09)

[2] Yang Yuehui. Literature Review of Agricultural Products E-commerce [J]. Journal of Anhui Agricultural Sciences, 2011 (18)

[3] QU Jian-ming, CHEN Jie.Application of FreeMarker Template Engine Dynamic Generation Page [J] .Computer \& Modernization, 2011 (03)

[4] Huang Hailong, Jiang Pingan, Zhang Xia, Wu Hongqi, Li Yong, Liu Hongpeng.Design and development of agricultural traceability system based on Web [J]. Xinjiang Agricultural Sciences, 2010 (09)

[5] Zhu Xiaoxiao. E-commerce website construction project demand analysis [J]. Heilongjiang Foreign Trade, 2010 (06) 